\title{
ANALISIS PELATIHAN SHIP MANAGEMENT GUNA MENINGKATKAN KUALITAS KERJA AWAK KAPAL DI PT. PERTAMINA PERKAPALAN JAKARTA
}

\author{
Yogi Pangestu dan Andy Wahyu Hermanto ${ }^{\text {b }}$ \\ ${ }^{a}$ Taruna (NIT. 51145519.K) Program Studi KALK PIP Semarang \\ ${ }^{\mathrm{b}}$ Dosen Program Studi KALK PIP Semarang
}

\begin{abstract}
PT. Pertamina Shipping Jakarta has training or training namely PMTC (Pertamina Marine Training Center) is a place to train employees to be able to improve the quality and quality of work, it has not gone well so it affects the quality of the crew's performance. The purpose of this study is to find out whether the ship management training program at PT. Pertamina Shipping Jakarta can reach the target optimally or not and to know the impact of the ship management training program on the quality of the work of the crew at PT. Pertamina Shipping Jakarta.

This research uses descriptive qualitative method by describing in detail the implementation of ship management training in order to improve the quality of work of the crew at PT. Pertamina Shipping Jakarta. Data collection is done by interview, observation, literature study and documentation conducted by the author.

The results of the study show that ship management training program at PT. Pertamina Shipping Jakarta has not reached its target optimally because there are still seafarers who have been on board the vessels that have not participated in the training, PT. Pertamina Shipping Jakarta lacks staff training staff, the pre test system has not been held before being given training. The impact of the ship management training program on the quality of the work of the crew as follows: ship management training on International Safety Management Code (ISM Code) makes the ship's crew understand more about international safety management standards in the operation of ships as well as efforts to prevent or control environmental pollution. carrying out Tank Cleaning, ship management training made the newly joined crew members aware of the work system and procedures when they later worked on the ship.
\end{abstract}

\section{Keywords: analysis, ship management training, work quality of ship crew}

\section{PENDAHULUAN}

PT. Pertamina Perkapalan merupakan salah satu perusahaan yang bergerak di bidang maritim atau pelayaran. PT. Pertamina Perkapalan berpusat di Jakarta, dimulai dengan dibentuknya Divisi Perkapalan Pertamina pada tahun 1959. Dengan armada dua unit kapal tanker draft rendah berkapasitas 3.220 DWT yang didapatkan dengan skema bare boat hire purchase (BBHP) atau sewa-beli jangka Panjang dari PT. Caltex. Seiring dengan berjalannya waktu, pada tanggal 6
Desember 1975, Presiden Soeharto mengeluarkan Dekrit Nomor 44, yang mengatur lebih lanjut keberadaan Direktorat Perkapalan dan Telekomunikasi (Dit. P\&T). Dalam kurun waktu inilah, Dit P\&T mencapai masa kejayaan dengan mengelola 133 unit kapal berbagai ukuran, dengan komposisi 77 unit tanker merupakan kapal milik sendiri, sedang kapal yang disewa dari pihak lain tidak lebih 60 unit. Selain itu Perkapalan juga mengelola 134 Pelabuhan Khusus (Pelsus) minyak dan gas, yang tersebar di seluruh Nusantara juga di bawah pengelola Dit. 
Yogi Pangestu dan Andy Wahyu Hermanto

P\&T. Serta seluruh sarana komunikasi elektronik kepunyaan Pertamina.

PT. Pertamina mempunyai Visi "Menjadi Perusahaan Energi Nasional Kelas Dunia", dan misinya adalah "Menjalankan usaha minyak, gas, serta energy baru dan terbarukan secara terintegrasi, berdasarkan prinsip-prinsip komersial yang kuat". Untuk mewujudkan Visi perseroan sebagai perusahaan kelas dunia, maka perusahaan milik Negara turut melaksanakan dan menunjang kebijakan dan program pemerintah di bidang ekonomi dan pembangunan nasional pada umumnya, terutama di bidang penyelenggaraan usaha energi, yaitu energi baru dan terbuka, minyak dan gas bumi baik dalam maupun di luar negeri serta kegiatan lain yang terkait atau menunjang kegiatan usaha di bidang energi, yaitu energi baru yang terbarukan, minyak dan gas bumi tersebut serta pengembangan optimalisasi sumber daya yang dimiliki perseroan untuk menghasilkan barang dan jasa yang bermutu tinggi dan berdaya saing kuat serta mengejar keuntungan guna meningkatkan nilai perseroan menjalankan usaha inti minyak gas, bahan bakar nabati serta kegiatan pengembangan, eksplorasi, produksi dan niaga energi baru dan terbarukan (new and renewable energy) secara terintegrasi.

Transportasi laut di Indonesia saat ini bisa dikatakan sedang mengalami masalah. Kecelakaan laut yang menelan banyak korban jiwa dan harta benda terjadi bergantian. Akar penyebab kecelakaan laut belum ditangani secara serius sehingga bahaya selalu mengintai pengguna jasa angkutan laut setiap saat. Sebagian besar kecelakaan di laut disebabkan karena kelalaian dari crew kapal (human error) itu sendiri. Dimana kesalahan itu merupakan kesalahan dalam pengoperasian kapal maupun penanganan muatan di kapal. Permasalahan yang timbul saat bekerja di atas kapal yang terjadi karena tidak diterapkannya konvensi STCW 197/95 (Standard of Training, Certification and
Watchkeeping for Seafarers) yang berisi tentang persyaratan pendidikan atau pelatihan yang harus dipenuhi oleh awak kapal atau crew untuk bekerja sebagai pelaut.

Manusia merupakan sumber daya terpenting, bukan hanya merupakan makhluk ciptaan Tuhan dan bukan saja manusia mempunyai rasa yang tentunya berbeda dengan makhluk lain, tetapi karena unsur-unsur lain yang harus dimiliki. Suatu perusahaan memiliki uang, modal, materi, mesin-mesin, metode kerja, waktu dan asetasetnya hanya dapat memberi manfaat jika manusianya mempunyai daya pembangunan dan bukan perusak bagi perusahaan. Kemajuan teknologi dimana peranan manusia telah banyak digantikan oleh mesin-mesin ternyata belum dapat menggantikan peran utama manusia dalam suatu perusahaan.

Dalam dunia bisnis usaha pelayaran diperlukan manusia yang benar-benar mampu melaksanakan suatu proses kegiatan pelayaran dan memahami kondisi kerja di lapangan, hal ini dikarenakan dalam manajemen transportasi laut berbeda dengan manajemen di perusahaanperusahaan yang bergerak dibidang lainnya. Perkembangan teknologi dan komputerisasi yang semakin pesat akan mempunyai dampak langsung terhadap proses produksi dalam suatu manajemen perusahaan terutama dalam meningkatkan kegiatan transportasi laut dimana dalam hal ini menyangkut kinerja tenaga kerja yang berkualitas.

PT. Pertamina Perkapalan menyediakan jasa penyediaan para pelaut yang terbaik. Dalam perekrutan para pelaut tersebut dilakukan penyeleksian dan pelatihan secara baik dan teliti, agar dapat menjadi para pelaut yang professional dan berdedikasi tinggi serta mampu berbahasa Inggris yang secara berkesinambungan selalu ditingkatkan kemampuannya, dengan selalu diadakan pelatihan ship management dan telah menjadi bagian integral dari pengembangan profesionalisme dan seluruh 
anggota awak kapal atau crew PT. Pertamina Perkapalan. Pelaksanaan pelatihan ship management dilakukan untuk meningkatkan performance atau kinerja dari seluruh awak kapal agar sesuai dengan kualifikasi yang dibutuhkan sebagai bagian dari profesionalisme pada saat ini PT. Pertamina Perkapalan mempunyai sekitar 600 orang pelaut.

PT. Pertamina Perkapalan mempunyai training atau diklat keterampilan sendiri yaitu PMTC (Pertamina Marine Training Centre) merupakan tempat untuk melatih para karyawan baik karyawan darat maupun karyawan laut agar dapat meningkatkan mutu dan kualitas dalam bekerja. Sehubungan dengan uraian di atas penulis terdorong untuk memilih judul tentang "Analisis Pelatihan Ship Management Guna Meningkatkan Kualitas Kerja Awak Kapal Di PT. Pertamina Perkapalan Jakarta”.

\section{METODOLOGI}

Metodologi penelitian yang dipakai dalam penelitian ini adalah metode deskriptif kualitatif, dimana peneliti mengambil data dengan mengadakan pengamatan sehingga penelitian yang dilakukan sesuai dengan metode yang digunakan. Menurut Whitney (2005:55), metode deskriptif adalah pencarian fakta dengan interpretasi yang tepat. Penelitian deskriptif mempelajari masalah-masalah dalam masyarakat, serta tata cara yang berlaku dalam masyarakat serta situasisituasi tertentu, termasuk tentang hubungan, kegiatan-kegiatan, sikap-sikap, pandangan-pandangan, serta proses-proses yang sedang berlangsung dan pengaruhpengaruh dari suatu fenomena. Menurut Nazir (2007:63) dalam buku "Contoh Metode Penelitian", metode deskriptif merupakan suatu metode dalam meneliti status sekelompok manusia, suatu objek, suatu set kondisi, suatu sistem pemikiran ataupun suatu kelas peristiwa pada masa sekarang. Tujuan dari penelitian deskriptif ini adalah untuk membuat deskripsi, gambaran, atau lukisan secara sistematis, faktual dan akurat mengenai fakta-fakta, sifat-sifat serta hubungan antar fenomena yang diselidiki. Sukmadinata (2009:18), menyatakan bahwa penelitian deskriptif bertujuan mendefinisikan suatu keadaan atau fenomena secara apa adanya. Dengan demikian dapat disimpulkan bahwa penelitian deskriptif kualitatif adalah penelitian yang dilakukan dengan cara mendeskripsikan peristiwa yang terjadi berdasarkan dokumen, gambar dan menganalisis data-data yang benar-benar ada, sehingga dapat dijadikan sebagai sumber penelitian tanpa menggunakan perhitungan angka atau penjumlahan.

\section{HASIL DAN DISKUSI}

\section{Apakah program pelatihan ship management bagi awak kapal yang dilaksanakan di PT. Pertamina Perkapalan Jakarta dapat mencapai target secara maksimal ?}

Pelatihan yang dilaksanakan di PT. Pertamina Perkapalan bagi para pelaut dirasakan penting agar para pelaut dapat beradaptasi terhadap situasi dan kondisi di atas kapal pada saat ini. Kegiatan pelatihan yang dilaksanakan di PT. Pertamina Perkapalan Jakarta terhadap para pelautnya adalah : ISM Code, Bridge Team Management, Tank Cleaning. Setiap pelaut yang akan naik ke kapal harus mengikuti pelatihan di atas, dan setiap pelatihan yang telah dijalankan akan mendapatkan sertifikat. Pelaksanaan program pelatihan ship management di PT. Pertamina Perkapalan Jakarta belum maksimal karena masih ada pelaut yang sudah di atas kapal yang belum sama sekali mengikuti pelatihan yang diadakan di departemen pelatihan PT. Pertamina Perkapalan karena pihak MPD (Marine Personal Departement) tidak benarbenar melaksanakan kegiatan pelatihan secara menyeluruh kepada awak kapal yang akan naik ke atas kapal dan 
Yogi Pangestu dan Andy Wahyu Hermanto

pengecekan dokumen karena keterbatasan waktu.

2. Bagaimana dampak program pelatihan ship management terhadap kualitas kerja awak kapal di PT. Pertamina Perkapalan Jakarta ?

Berdasarkan hasil pengamatan awal yang dilakukan oleh penulis terdapat suatu perbedaan terhadap kinerja awak kapal setelah diberikan pelatihan ship management di PT. Pertamina Perkapalan Jakarta. Dampak atau pengaruh yang ditimbulkan setelah awak kapal mengikuti program pelatihan ISM Code, Bridge Team Management, Tank Cleaning di PT. Pertamina Perkapalan Jakarta yang membuat para awak kapal dapat mengetahui dan mempelajari sistem dan prosedur kerja pada saat bekerja di atas kapal milik PT. Pertamina Perkapalan Jakarta. Dari adanya hal tersebut dapat menjadikan awak kapal yang berada di atas kapal milik PT. Pertamina Perkapalan Jakarta akan lebih berkompeten dan dapat meningkatkan kualitas kerja awak kapal pada saat bekerja di atas kapal milik perusahaan.

\section{PEMBAHASAN MASALAH}

1. Apakah program pelatihan ship management bagi awak kapal yang di laksanakan di PT. Pertamina Perkapalan Jakarta dapat mencapai target secara maksimal ?

Berdasarkan observasi dan dokumentasi yang dilakukan peneliti pada saat melaksanakan praktek darat, program pelatihan ship management yang dilaksanakan di PT. Pertamina Perkapalan Jakarta masih belum mencapai target secara maksimal karena masih ada pelaut yang sudah di atas kapal yang belum sama sekali mengikuti pelatihan yang diadakan oleh departemen pelatihan di PT. Pertamina Perkapalan Jakarta. Hal ini disebabkan karena pihak MPD (Marine Personal Department) atau selaku pihak yang melaksanakan kegiatan pelatihan kepada seluruh crew yang bekerja di PT. Pertamina Perkapalan Jakarta tidak memiliki waktu yang cukup untuk melaksanakan kegiatan pelatihan secara menyeluruh kepada awak kapal yang akan naik ke atas kapal dengan waktu yang singkat dan memeriksa kelengkapan sertifikat ataupun dokumen dari awak kapal yang akan naik ke atas kapal tersebut. Sering kali waktu perekrutan yang terbatas sehingga pihak MPD dituntut untuk segera menyelesaikan urusan administrasi crew tersebut. Adapun kegiatan pelatihan yang dilakukan di PT. Pertamina Perkapalan terhadap para pelaut antara lain :

a. International Safety Management Code (ISM Code).

Program pelatihan ini dirancang agar para pelaut mengetahui secara mendalam apa itu ISM Code, kenapa ISM Code ada, kapan ISM Code diberlakukan dan apa yang harus dilakukan di atas kapal agar sesuai dengan elemen-elemen ISM Code.

b. Bridge Team Management

Program pelatihan ini dirancang dengan maksud dan tujuan untuk memberikan dukungan kepada team anjungan dalam mempersiapkan suatu pelayaran agar kapal bisa aman berlayar diantara pelabuhanpelabuhan atau dari dermaga ke dermaga.

c. Tank Cleaning

Program pelatihan ini dirancang agar para pelaut bagian mesin mengetahui prosedur pembersihan kotoran di dalam tank yang sangat penting dan sangat luas agar pengoperasian kapal dapat lebih efektif dan selamat.

Setiap pelaut yang akan naik ke kepal harus mengikuti pelatihan di atas, dan 
setiap pelatihan yang telah dijalankan akan mendapatkan sertifikat. Kendala yang dihadapi dalam pencapaian sasaran program pelatihan yang dilaksanakan di PT. Pertamina Perkapalan selama penulis melaksanakan praktek darat, antara lain :

a. Masih ada para pelaut yang sudah di atas kapal yang belum sama sekali mengikuti pelatihan yang diadakan di Departemen Pelatihan PT. Pertamina Perkapalan karena pihak MPD (Marine Personal Department) tidak benar-benar melaksanakan kegiatan pelatihan secara menyeluruh kepada awak kapal yang akan naik keatas kapal dan melakukan pengecekan dokumen atau sertifikat sebelum pelaut tersebut naik ke kapal, pada hal ini menandakan program pelatihan di PT. Pertamina Shipping belum maksimal karena masih adanya beberapa prosedur yang terlewatkan yang berdampak pada pemberian pelatihan kepada awak kapal yang belum menyeluruh, sehingga terdapat beberapa awak kapal yang sudah naik ke atas kapal namun belum melaksanakan program pelatihan karena keterbatasan waktu yang ada.

b. Pada saat ini di Departemen Pelatihan di PT. Pertamina Perkapalan kekurangan personil, idealnya dalam suatu Departemen Pelatihan harus ada training manager, training koordinator, harus ada trainernya minimal 4 orang untuk deck dan engine, kenyataan pada saat sekarang ini di Departemen Pelatihan di PT. Pertamina Perkapalan hanya terdapat 2 training staff untuk deck dan 2 training staff untuk engine.

c. Pada Departemen Pelatihan PT. Pertamina Perkapalan belum diadakan sistem pree test sebelum diberi pelatihan hanya diberikan post test setelah pelatihan sehingga perbandingan pengetahuan para pelaut sebelum diberi pelatihan dan sesudah diberi pelatihan tidak diketahui.

\section{Bagaimana dampak yang ditimbulkan dari terhambatnya penataan container ekspor pada container yard?}

Berdasarkan observasi dokumentasi dan hasil wawancara yang dilakukan peneliti pada saat melaksanakan penelitian, maka dapat diperoleh beberapa data yang ada, peneliti dapat menganalisis berbagai permasalahan yang ada di Departemen Pelatihan PT. Pertamina Perkapalan yang berkaitan dengan pelaksanaan pelatihan dalam rangka meningkatkan mutu para pelaut yang bekerja di atas kapal. Untuk dapat mengetahui sejauh mana dampak peranan Departemen Pelatihan di PT. Pertamina Perkapalan dalam meningkatkan mutu awak kapal dan kualitas kerja awak kapal di perusahaan. Selanjutnya peneliti uraikan dampak atau pengaruh dari program pelatihan ship management terhadap kualitas kerja awak kapal PT. Pertamina Perkapalan Jakarta adalah sebagai berikut:

a. Dengan dilaksanakannya pelatihan ship management mengenai International Safety Management Code (ISM Code) yang diikuti oleh awak kapal yang akan bekerja di PT. Pertamina Perkapalan Jakarta menjadikan awak kapal yang akan naik ke atas kapal milik perusahaan lebih paham tentang standar internasional manajemen keselamatan dalam pengoperasian kapal serta upaya pencegahan atau pengendalian pencemaran lingkungan dan dapat meningkatkan kesadaran para awak kapal tentang pentingnya faktor manusia, serta perlunya meningkatkan manajemen operasional kapal dalam mencegah terjadinya kecelakaan kapal, manusia, muatan dan harta benda, serta dapat mencegah terjadinya pencemaran lingkungan laut dan mengetahui bagaimana prosedur yang benar dan 
Yogi Pangestu dan Andy Wahyu Hermanto

aman dalam melaksanakan proses bongkar atau muat Bahan Bakar Minyak (BBM) dan Gas yang dilakukan dari tangki muatan kapal ke dermaga atau sebaliknya. Selain itu apabila terjadi keadaan darurat, kecelakaan dan kejadian berbahaya seperti halnya terjadinya tumpahan minyak pada saat proses bongkar muat para awak kapal sudah mengerti akan prosedur yang harus dilaksanakan untuk menanganinya agar tidak menyebabkan terjadinya pencemaran di sekitar perairan tersebut. Program pelatihan ini merupakan salah satu cara untuk meningkatkan kinerja awak kapal yang berkualitas baik dan berkompeten agar dapat bekerja dengan baik pada saat di atas kapal. Seperti yang peneliti dapatkan melalui wawancara terbuka dengan Chief officer yaitu sebagai berikut: "Pelatihan International Safety Management Code (ISM Code) yang diberikan oleh perusahaan kepada awak kapal di PT. Pertamina Perkapalan Jakarta meberikan dampak yang baik untuk para awak kapal disini, setelah diberikan pelatihan tersebut para awak kapal dapat menerapkan apa yang mereka dapatkan pada saat pelatihan pada saat bekerja, pada saat di atas kapal para awak dapat menerapkan pemahaman mereka tentang standar internasional manajemen keselamatan dalam pengoperasian kapal dan bagaimana cara pencegahan atau pengendalian pencemaran lingkungan pada saat terjadinya keadaan darurat, kecelakaan dan kejadian berbahaya".

b. Dengan dilaksanakannya pelatihan ship management mengenai Tank Cleaning para awak kapal lebih mengerti secara mendalam bagaimana prosedur pelaksanaan tank cleaning yang benar dan sesuai aturan yang harus dilakukan. Seperti halnya pelaksanaan kegiatan Tank Cleaning harus dilakukan pada jarak lebih dari 50 mil dari daratan atau pelabuhan terdekat dan pada saat pelaksanaan tank cleaning para awak kapal telah menggunakan alat keselamatan yang sesuai dengan aturan yang berlaku, sesuai dengan apa yang telah awak kapal dapatkan pada saat mengikuti program pelatihan, hal tersebut dapat meminimalisir terjadinya kecelakaan kerja pada saat pelaksanaan kegiatan tersebut. Dari hasil wawancara yang dilakukan peneliti kepada salah satu awak kapal yang telah mengikuti pelatihan Tank Cleaning di PT. Pertamina Perkapalan Jakarta mengatakan bahwa, "Setelah mengikuti pelaksanaan pelatihan Tank Cleaning di PT. Pertamina Perkapalan Jakarta para awak kapal dapat melaksanakan kegiatan Tank Cleaning sesuai prosedur yang telah ditetapkan, para awak kapal sudah memahami tentang bagaimana melaksanakan kegiatan tersebut secara efisien dan meminimalisir kecelakaan kerja pada saat melaksanakan kegiatan tersebut, dengan begitu pelatihan Tank Cleaning yang diberikan PT. Pertamina Perkapalan Jakarta terhadap para awak kapal berdampak baik bagi awak kapal yang akan naik ke atas kapal milik PT. Pertamina Perkapalan Jakarta".

c. Untuk awak kapal yang baru bergabung di PT. Pertamina Perkapalan yang sebelumnya belum mengetahui atau memahami bagaimana sistem kerja dan prosedur bekerja di atas kapal dengan baik maka pada saat sebelum awak kapal tersebut naik ke kapal dilakukan pelatihan ship management mengenai International Safety Management Code (ISM Code), Bridge Team Management dan Tank Cleaning yang membuat para awak kapal dapat 
mengetahui akan sistem dan prosedur kerja pada saat bekerja di atas kapal milik PT. Pertamina Perkapalan Jakarta. Dari adanya hal tersebut dapat menjadikan awak kapal yang berada di atas kapal milik PT. Pertamina Perkapalan Jakarta akan lebih berkompeten dan dapat meningkatkan kualitas kerja awak kapal pada saat bekerja di atas kapal milik perusahaan. Dari hasil wawancara yang dilakukan peneliti kepada salah satu awak kapal yang baru bergabung dan telah mengikuti kegiatan pelatihan di PT. Pertamina Perkapalan Jakarta mengatakan bahwa, "Pelatihan yang diberikan oleh PT. Pertamina Perkapalan Jakarta berdampak baik terhadap awak kapal kapal yang baru saja bergabung di perusahaan, yang sebelumnya para awak kapal belum mengetahui atau memahami bagaimana sistem kerja dan prosedur bekerja di atas kapal dengan baik setelah diberikan pelatihan ISM Code, Bridge Team Management, Tank Cleaning menjadikan awak kapal yang berada di atas kapal milik PT. Pertamina Perkapalan Jakarta akan lebih berkompeten dan dapat meningkatkan kualitas kerja awak kapal pada saat bekerja di atas kapal milik perusahaan".

\section{KESIMPULAN}

Berdasarkan pembahasan yang telah dikemukakan dalam bab-bab sebelumnya, dalam bab ini penulis akan mengambil kesimpulan lalu dapat kita ketahui dari Analisis pelatihan ship management guna meningkatkan kualitas kerja awak kapal di PT. Pertamina Perkapalan Jakarta. Dari pembahasan di atas maka dapat ditarik kesimpulan sebagai berikut:

1. Program pelatihan ship management bagi awak kapal yang di laksanakan di PT. Pertamina Perkapalan Jakarta : a. Masih ada para pelaut yang sudah di atas kapal yang belum sama sekali mengikutipelatihan yang diadakan di Departemen Pelatihan PT. Pertamina Perkapalan karena pihak MPD (Marine Personal Department) tidak benar-benar melaksanakan kegiatan pelatihan secara menyeluruh kepada awak kapal karena keterbatasan waktu yang ada.

b. PT. Pertamina Perkapalan kekurangan personil, idealnya dalam suatu Departemen Pelatihan harus ada training manager, training koordinator, harus ada trainernya minimal 4 orang untuk deck dan engine untuk saat ini hanya terdapat 2 training staff untuk deck dan 2 training staff untuk engine.

c. Belum diadakannya sistem pree test sebelum diberi pelatihan hanya diberikan post test setelah pelatihan sehingga perbandingan pengetahuan para pelaut sebelum diberi pelatihan dan sesudah diberi pelatihan tidak diketahui.

2. Dampak program pelatihan ship management terhadap kualitas kerja awak kapal di PT. Pertamina Perkapalan Jakarta adalah:

a. Dengan dilaksanakannya pelatihan ship management mengenai International Safety Management Code (ISM Code) menjadikan awak kapal yang akan naik ke atas kapal lebih paham tentang standar internasional manajemen keselamatan dalam pengoperasian kapal serta upaya pencegahan atau pengendalian pencemaran lingkungan.

b. Pelaksanaan pelatihan ship management mengenai Tank Cleaning menjadikan para awak kapal lebih mengerti secara mendalam bagaimana prosedur pelaksanaan yang benar dan sesuai aturan yang harus dilakukan.

c. Untuk awak kapal yang baru bergabung di PT. Pertamina Perkapalan, pelatihan ship 
Yogi Pangestu dan Andy Wahyu Hermanto

management membuat para awak kapal dapat mengetahui akan sistem dan prosedur kerja pada saat bekerja di atas kapal milik PT. Pertamina Perkapalan Jakarta.

3. Upaya yang harus dilakukan untuk mengatasi terhambatnya penataan container ekspor adalah sebegai berikut:

a. PT. Pertamina Perkapalan sebaiknya menambahkan jumlah pelatih atau trainer staff yang ada, dengan bertambahnya jumlah pelatih diharapkan dapat mengefektifkan pelaksanaan pelatihan sehingga keseluruhan para awak kapal dapat melaksanakan pelatihan ship management sesuaidengan jadwal yang telah ditetapkan oleh pihak training staff dan hendaknya sebelum diberi pelatihan para peserta pelatihan diberi soal pre test terlebih dahulu tentang materi yang akan diberikan dan setelah selesai pelatihan diberi post test sehingga dapat digunakan sebagai perbandingan apakah program pelatihan yang telah dilaksanakan dapat meningkatkan pengetahuan para pesertanya.

b. Sebelum melaksanakan program pelatihan hendaknya perusahaan melakukan dan merencanakan program-program pelatihan yang akan dilaksanakan secara maksimal dan selalu update atau terbarui bertujuan agar program pelatihan yang akan dilaksanakan dapat berjalan sesuai dengan yang diharapkan. Kegiatan tersebut sangat penting untuk menjamin agar kegiatan pelatihan benar benar maksimal guna mencapai tujuan baik jangka pendek maupun untuk jangka panjang.

\section{DAFTAR PUSTAKA}

Dewey, Jhon. 2007. How We Think. New York : Isha Books
Downard, Jhon M. 2014. Ship Management Saries Running Costs. Brimingham : Fairplay Publication

Kaswan. 2014. Pelatihan dan Pengembangan Untuk Meningkatkan Kinerja SDM, CV. Alfabeta, Bandung

Matutiana. 2001. Manajemen Sumber Daya Manusia. Jakarta : Gramedia Widia Sarana Indonesia

Nazir, Moh. 2007. Metode Penelitian. Jakarta : CV. Ghalia Indonesia

Noor, Julaiansyah. 2014. Metodelogi Penelitian. Jakarta : CV. Kencana

Pramudyo. 2014. Pelatihan dan Pengembangan untuk Meningkatkan Kinerja SDM. Bandung : CV. Alfabeta

PIP Semarang. 2017. Pedoman Penyusunan Skripsi. Semarang : PIP Semarang

Soewedo. 2007. Manajemen Perusahaan Pelayaran. Pasuruan : CV. Rajawali Pers

Sugiono. 2007. Metodelogi Penelitian. Bandung : CV. Alfabeta

Sugiyono. 2014. Statistika Untuk Penelitian. Bandung : CV. Alfabeta

Sujarweni. 2014. Metodelogi Penelitiam. Yogyakarta : CV. Pustaka Baru Press

Umar. 2014. Manajemen Pendidikan dan Pelatihan. Surakarta : CV. Pustaka Setia

Wilson dan Hayel. 1987. Hand Book Of Modern Office Management and Administration Service. New Jersey : Mc Graw Hill Inc 
Presiden Republik Indonesia. UndangUndang RI No.17 Tentang Pelayaran. Jakarta

Keputusan Menteri Perhubungan Republik Indonesia Nomor PM 70. 2014. Pengawakan Kapal Niaga. Jakarta

http://www.kbbi.web.id/2016/data.html015 /09/http://www.kbbi.web.id/2016/a nalisis.html

http://www.wikipedia.web.id/1978/STCW.h tml 